\title{
Atlas Histórico de América: Pueblos Originarios
}

\section{Luis Andrés Valenzuela Olivares*}

El Atlas Histórico de América es una iniciativa de la Comisión de Historia para la agenda correspondiente al año 2017, la cual había estado promulgada para ser un proyecto de Asistencia Técnica del Instituto Panamericano de Geografía e Historia (IPGH).

En la Tercera Reunión Conjunta de las Comisiones, realizada en la Ciudad de México 2015, se solicitaron nuevos comités que desarrollaran proyectos de Asistencia Técnica. En esa oportunidad el maestro Luis Valenzuela, de Chile, solicitó la creación del Comité de Cartografía Histórica que hasta la fecha coordina.

Como nuevo comité se realizaron reuniones que coordinarán e integran nuevos miembros; en esta ocasión la mesa del comité de Cartografía Histórica la llevaron su coordinador, Luis Valenzuela (Chile); Jorge Ortiz-Sotelo (Perú) y Filiberto Santa Cruz (República Dominicana); también estuvo presente Chester Zelaya Goodman, quien apoyaba a los nuevos comités en la priorización de funciones (Imagen 1).

Uno de los compromisos fuertes que adquirió el comité de Cartografía Histórica fue desarrollar el Atlas Histórico de América por medio de los Proyecto de Asistencia Técnica (PAT). Proyecto que ya la doctora Patricia Galeana había comenzado a desarrollar en un esquema de lo que debería ser el Atlas. La doctora Galeana nos resumía el Atlas como:

...El Atlas Histórico de América podría incluir tanto la geografía física como humana, y la antropología desde los primeros asentamientos humanos hasta la actualidad. Lo mismo daría cuenta de la llegada de los europeos, de las campañas insurgentes; la consolidación de los Estados nacionales; los límites territoriales;

* Coordinador proyecto PAT-2017 Atlas Histórico de América: Pueblos Originarios. Coordinador del Comité de Cartografía Histórica de la Comisión de Historia del IPGH, correo electrónico: 1valenzuelaolivares@gmail.com. 
y los problemas actuales: el cambio climático y los energéticos, los movimientos migratorios y el narcotráfico...

Desde este punto, el comité de Cartografía Histórica comienza a desarrollar el Atlas Histórico de América. Un libro que emplazara los desafíos que nombraba la doctora Galeana y que formulara una continuidad de investigaciones más recientes.

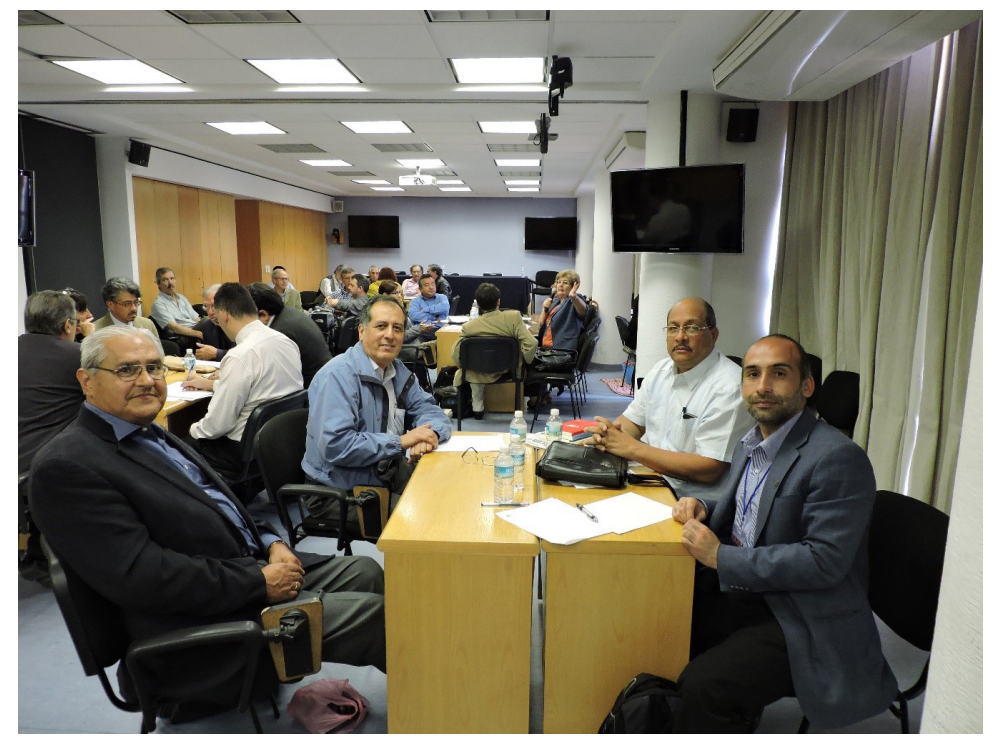

Imagen 1. Tercera Reunión Técnica Conjunta de las Comisiones. Comité de Cartografía Histórica, 2015.

Es así como los integrantes del comité, especialmente el coordinador Luis Valenzuela y Jorge Ortiz-Sotelo se reúnen en Santiago de Chile aprovechando la visita de éste para revisar el esquema y decidir ajustes que marcarán una potencialidad al Atlas.

En esa reunión informal se presentaron tres puntos a considerar en el Atlas:

1. La división de volumen que representarán al sujeto de estudio, en este caso, a los Pueblos Originarios, Extranjeros (colonias), Mestizos (conformando

1 Correo enviado por la doctora Patricia Galeana a los miembros del nuevo comité: 23 de junio de 2015. 
lo que hoy llamamos República), tanto para épocas como antecedentes que cubran a todos los individuos de la región americana.

2. Orientarlo a nuevas investigaciones, ya que el incluir a las grandes civilizaciones o estudios, nuevamente dejaría afuera a estudios locales más recientes, las que serían integradas por un llamado a participar y exponer en un Seminario Internacional.

3. Que el Atlas incluyera una versión digital e interactiva como la impresión de un Volumen que distinguiera el sujeto de estudio y fuera antecedente para la educación en América.

De esta manera el Atlas Histórico de América se comenzó a trabajar para postularlo a los proyectos de Asistencia Técnica PAT-2017 a las comisiones de Historia y Cartografía, entre noviembre de 2015 y abril de 2016. El anteproyecto tomó los puntos anteriormente señalados y especificaba que el sujeto de estudio sería los Pueblos Originarios y que la coordinación de este primer proyecto del Comité sería asumida por su coordinador.

Después de varios acuerdos por correo electrónico, así como reuniones de los tres miembros, con el copatrocinio de la Universidad Andrés Bello, dirigida por el doctor Mario Prades como director subrogante de la licenciatura en Historia de dicha casa de estudios, se fue armando el anteproyecto para ser presentado al Instituto. Además, el coordinador se acercó a la empresa ESRI Chile, cuyo gerente, Felipe San Martín, se mostró dispuesto a ser parte de esta iniciativa, y además, nos mostró las nuevas herramientas de visualización por la web, específicamente del software Story Maps, así como las garantías y soluciones a proyectos ONG sin fines de lucro. Con toda esta información y apoyo se postuló a los Proyectos de Asistencia Técnica PAT-2017 como “Atlas Histórico de América: Pueblos Originarios".

Este proyecto se realizaría con un llamado a participar en el primer Seminario Internacional Atlas Histórico de América. Las ponencias (resúmenes) se utilizarían para efectuar un Atlas digital por medio de herramientas electrónicas que mostraran tanto videos, imágenes y mapas en forma interactivas, en este caso del software Story Maps. Dejando para un segundo proyecto el volumen impreso (borrador).

También se invitaría a participar a expertos internacionales, quienes proporcionarían las pautas y ejes de cada mesa de trabajo del seminario. Esto se desarrollaría una vez aprobado el proyecto, lo que dejaría un corto espacio para integrar más investigaciones recientes.

La respuesta de aprobación llegó el 15 de diciembre de 2016 a través de correo electrónico, así fue posible estructurar la convocatoria para participar en el seminario a principios del año siguiente.

De los fondos solicitados sólo se aprobó un 35\% de lo pedido al IPGH; esto nos urgió replantear y reestructurar los objetivos específicos, pero no los 
generales, pues no podíamos olvidar que la esencia era el Atlas; de esta forma comenzó toda una travesía para ampliar los recursos por medio de empresas privadas.

\section{Desarrollo}

Una vez confirmada la aprobación y el apoyo del IPGH, el equipo comienza a trabajar en un logotipo y una página web que fueran imagen del Atlas. Aunque las reuniones de coordinación con los miembros (Luis Valenzuela, Jorge OrtizSotelo, Filiberto Cruz Sánchez) no eran siempre presenciales, cada decisión y desarrollo de las etapas fueron aprobados por todos.

El logo debía contener los textos del Atlas Histórico de América y debería ser utilizado para todas las ocasiones. La primera imagen que nos entregó la diseñadora fue una región de América en blanco y negro, la cual fue descartada por los miembros, quienes impusieron que la región americana era tan diversa que una imagen debería comprender y representarlo por colores. Así, el diseño quedó establecido por un mapa de la región arqueado hacia el oriente y con los países en tonos marrones al amarillo sin distinguir los límites administrativos. De esta manera, también se integró nuestro lema que atraería a los investigadores y académicos a ser parte de esta iniciativa. Todos los miembros quedamos de acuerdo en que el lema presentara la oportunidad de observar al sujeto tanto macro como micro y que se estableciera una cercanía con todas las ciencias sociales, principalmente con las áreas de la comisión de Historia (Antropología, Arqueología e Historia). Nuestro lema es: "Nuevas miradas en la huella del americano".

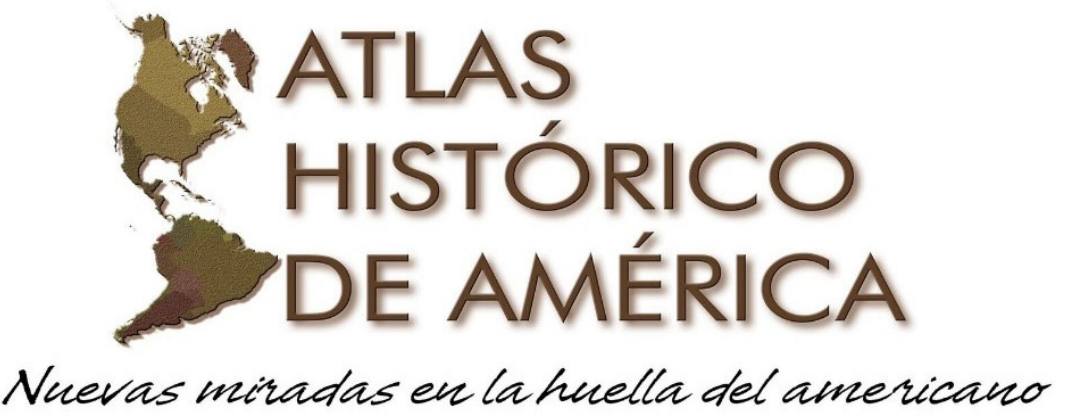

Imagen 2. Logo Atlas Histórico de América. 
La página web se fue desarrollando a medida que se cumplían las etapas y procesos, para ello fue necesario contar con un programador y un diseñador que realizaran estos cambios oportunamente, como la revisión y el manejo de spam que podría afectar a las propuestas que llegaran. A la fecha, la página web ha sufrido varias modificaciones de imágenes, textos, colores, documentos anexos, ubicación y contactos, dependiendo de las necesidades.

Contar con invitados principales representa una gran ventaja, pues la presencia de prestigiosos académicos e investigadores internacionales consolidan las redes de contacto con otros miembros. Queremos agradecer el apoyo que nos brindó Miguel Lecaros, nuestro primer invitado, ya que su apoyo - en fechas de asueto en nuestro país - fue crucial para reunirnos con el doctor Rubén Stenhberg, director del área de Antropología del Museo Nacional de Historia Natural de Chile, y quien aceptó participar en una de las mesas. También fue fundamental el apoyo de Hugo Betancourt, quien logró contactar al doctor Federico Navarrete Linares, de la Universidad Autónoma de México, quien es un referente por su obra sobre el mesoamericanismo. De igual manera, el doctor Clifford Trafzer nos apoyó en contactar a la doctora Michelle Raheja, Directora del Centro de California para las Naciones Nativas (CCNN por sus siglas en inglés) de la University of California, Riverside, quien estuvo muy complacida en ser parte de este Atlas y del seminario. El doctor Jorge Pinto, premio nacional de Historia en Chile y un experto en los conflictos de la Araucanía, aceptó la invitación gracias a que el coordinador del proyecto había sido estudiante de sus seminarios.
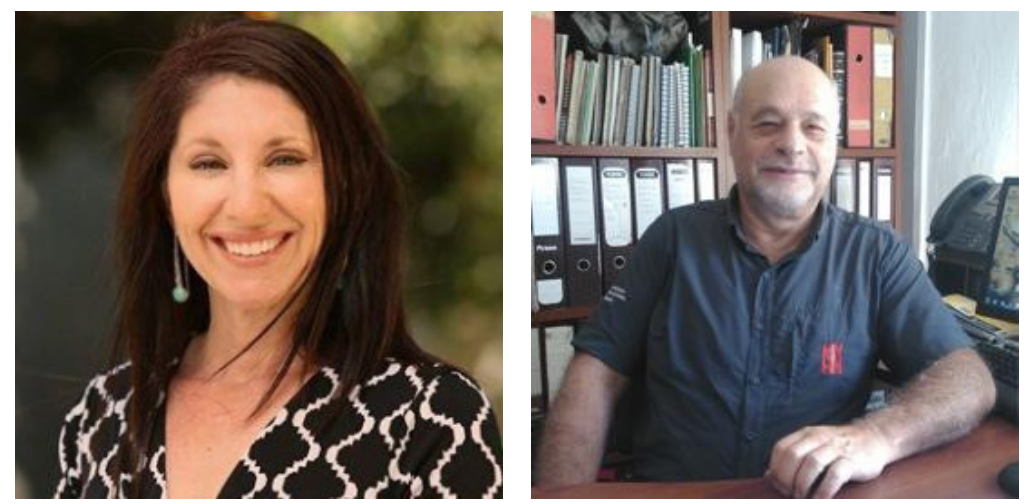

Imagen 3. Michelle Raheja y Rubén Stenhberg, invitados principales al Seminario. 

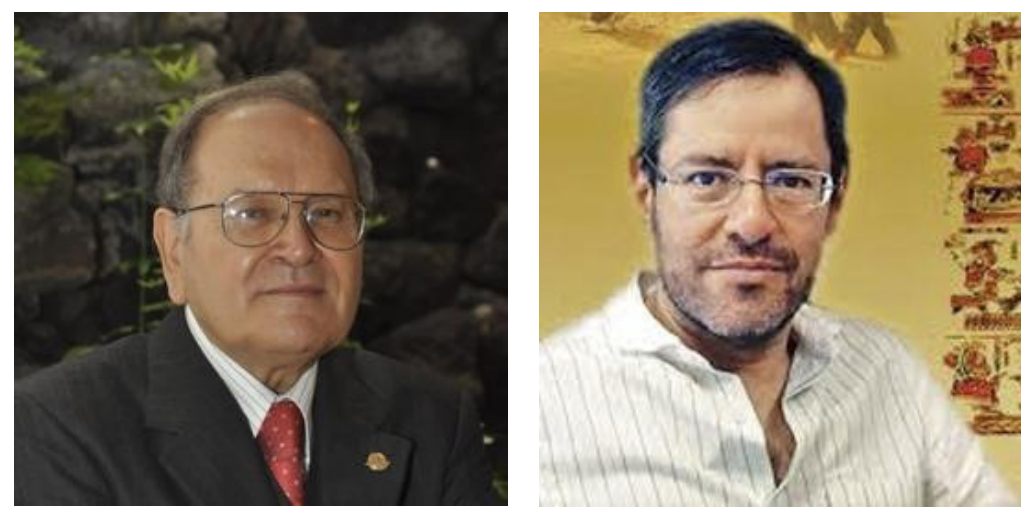

Imagen 4. Jorge Pinto y Federico Navarrete, invitados principales al Seminario.

La institución copatrocinadora del proyecto, Universidad Andrés Bello, estableció realizar el seminario en las fechas 13 y 14 de noviembre para tener una capacidad mayor de postulante, y la factibilidad de utilizar sus dependencias tanto para reuniones como para el mismo seminario, contando con el apoyo del Archivo Nacional de Chile, el cual siempre ha dispuesto sus instalaciones, especialmente en un evento internacional como fue el Atlas Histórico de América.

Como al principio se comentaba, ante el escaso financiamiento se buscó el apoyo externo, como la empresa ESRI Chile, distribuidores del software ArcGIS Online, el cual en su plataforma de publicación tiene la herramienta Story Maps, aunque el valor de la licencia corresponde al año de servicio y utilización de servidores donde se aloja la aplicación. Estas limitantes impidieron el auspicio del software, pero su gerente se comprometió a brindar el servicio de coffe break durante el evento.

Por otra parte, la empresa Geosystemas nos subsidió el software ArcGIS Online por un año de servicio con la única condición de presentar una herramienta de recorridos virtuales por lugares patrimoniales. De esta forma, la Empresa, la Universidad y el Museo de Historia Natural de Chile firmaron un acuerdo el 24 de octubre de 2017 para realizar el "Tour $360^{\circ}$ ", el cual se presentaría en el seminario internacional.

Otro auspiciador fue la empresa de turismo Turistik, quienes nos ofrecieron 25 pases Hop on Hop off, consistente en un recorrido por los lugares más emblemáticos de Santiago de Chile. Este viaje fue entregado a cada exponente y participante del seminario y se realizó el día 15 de noviembre de 2017.

Para la difusión del Seminario se realizaron visitas a los diferentes centros académicos de las Universidades, museos y espacios que difundieran la Historia y el patrimonio, radio, redes sociales, entre otros. Aunque no fue posible la 
difusión presencial internacional se utilizó tanto la red de profesionales del IPGH, las plataformas de boletín y redes sociales de la comisión de Historia, así como de la Universidad Andrés Bello y del comité de Cartografía Histórica. De esta manera se entregaban los posters informativos realizados en español e inglés, este último para ampliar la difusión a los países de habla inglesa y una cobertura internacional (véanse Imágenes 5 y 6).

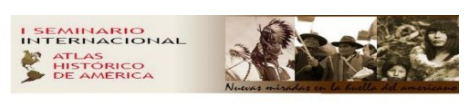

\section{CONVOCATORIA}

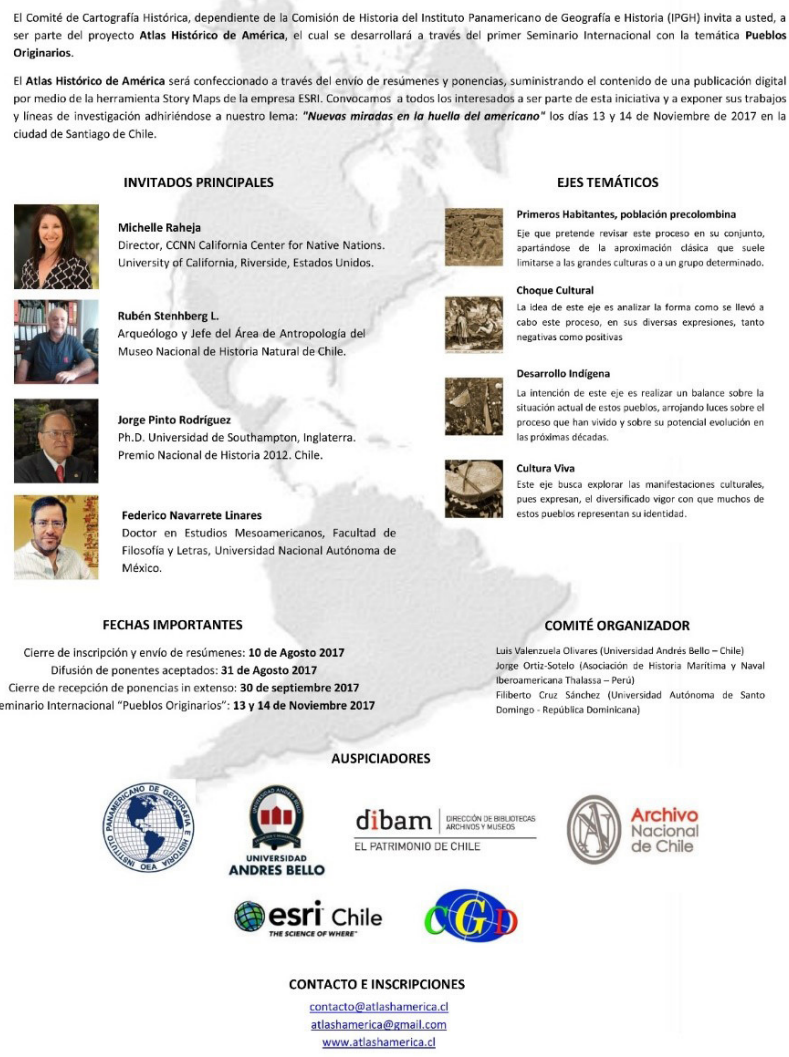

Imagen 5. Afiche de llamado para postular al Seminario Internacional en versión español. 


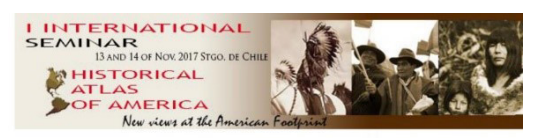

ANNOUNCEMENT

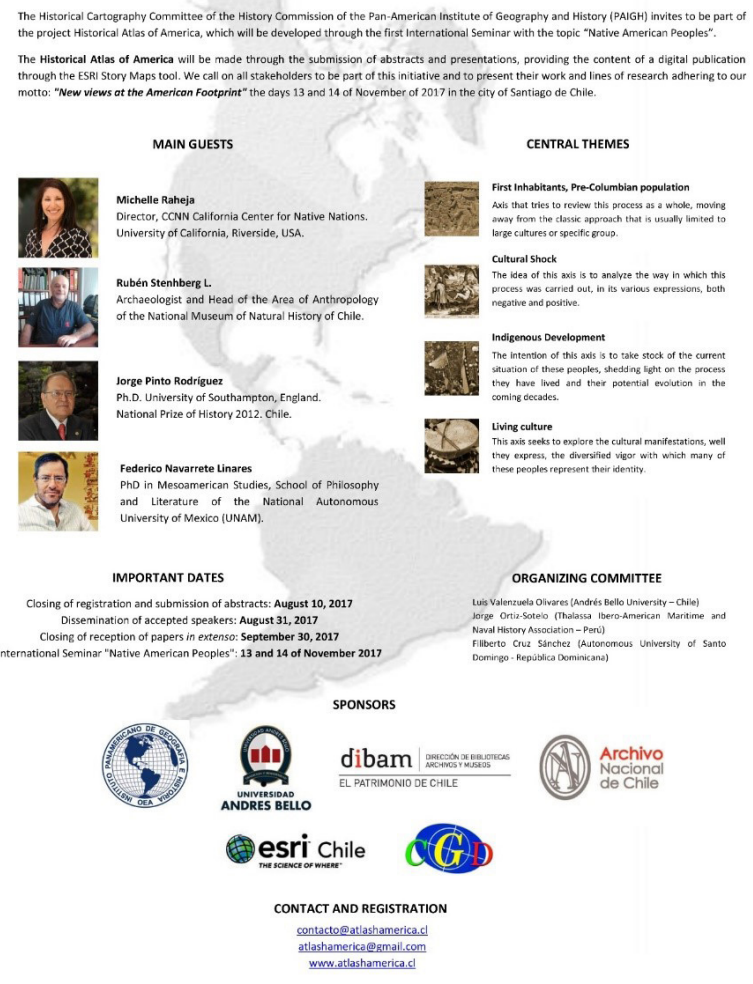

Imagen 6. Afiche de llamado para postular al Seminario Internacional en versión inglés.

Esta amplia convocatoria atrajo a participantes de diversas partes del mundo. El listado de ponentes por país corresponde e incluye a los cuatro invitados principales. Para la clasificación por ejes temáticos sólo se mencionan los exponentes aceptados y confirmados en la participación del seminario. No se incluyen las dos charlas de las empresas auspiciadoras, ESRI Chile y Geosystemas.

Por país: Austria, uno; Argentina, tres; Chile, siete; España, uno, México, seis; Perú, uno; República Dominicana, uno; Estados Unidos, uno. Por ejes: Primeros Habitantes con tres exponentes, Choque Cultural con siete, Desarrollo Indígena con tres exponentes y Cultura Viva con dos. 
Respecto a las afiliaciones de los participantes se encuentran desde centros de cultura hasta universidades. El listado de cada una de ellas se indica a continuación: Universidad Bernardo O’Higgins, Chile; TEFROS, Universidad Nacional de Río Cuarto, Argentina; Centro de Investigaciones en Antropología Social, CIESAs Peninsular, México; Karl-Franzens-Universität Graz, Austria; Universidad Adolfo Ibáñez; Sociedad de Estudios Históricos, Arqueológicos y Geográficos de Chile; Universidad de la Defensa, Argentina; Universidad Autónoma de México; Academia de Humanismo Cristiano, Chile; Universidad Metropolitana de Ciencias de la Educación, Chile; Universidad de Buenos Aires, Argentina; Universidad de Guanajuato, México; Universidad Autónoma de Barcelona, España; Exhi-Premagallania, Chile; Universidad Nacional Mayor de San Marcos, Perú; Universidad Autónoma de Santo Domingo, República Dominicana; Universidad de La Frontera de Temuco, Chile; Museo Nacional de Historia Natural, Chile; California Center for Native Nations, University of California Riverside, Estados Unidos.

El I Seminario Internacional Atlas Histórico de América se realizó de acuerdo a los protocolos establecidos. El primer día de exposiciones se inauguró con la presencia de destacados miembros del Instituto Panamericano de Geografía e Historia, la vicepresidenta del IPGH, señora Alejandra Coll Escanilla; el presidente de la Sección Nacional de Chile (s), Coronel Carlos Prado Casanova; la directora de la licenciatura en Historia de la Universidad Andrés Bello, señora Solène Bergot; el director de la licenciatura en Cartografía y Geomática de la Universidad Tecnológica Metropolitana, señor Pablo Azocar. La apertura y discurso de bienvenida la entregó el coordinador del proyecto, Luis Valenzuela Olivares, para luego pasar a las conferencias inaugurales de tres mesas (Cultura Viva, Desarrollo Indígena y Primeros Habitantes), comenzando por Michelle Raheja, Federico Navarrete y Rubén Stenhberg, respectivamente, mesa que fue moderada por nuestro comité científico a cargo de Mario Prades. El segundo bloque fue informativo donde las empresas auspiciadoras dieron a conocer sus avances y proyectos en materias patrimoniales. La empresa Geosystemas presentó "Tour $360^{\circ}$ Chile Biogeográfico Museo Nacional de Historia Natural" a cargo del gerente general, Roberto Muñoz; ESRI Chile presentó “ArcGIS como plataforma de colaboración para una comunidad viva y dinámica del mundo de las geotecnologías", a cargo del señor Daniel Flores. La sección de la tarde fue estructurada incluyendo dos mesas de presentaciones, las que fueron expuestas por los señores Ricardo Loyola, Brus Leguas, Eugenio Rivas y Norberto Mollo, ambas mesas fueron moderadas por nuestro miembro del comité y proyecto, Jorge Ortiz-Sotelo.

El segundo día de exposiciones, realizado en el Salón Ricardo Donoso del Archivo Nacional de Chile, las exposiciones comenzaron con la mesa Desarrollo Indígena, moderada por el coordinador del proyecto. Los exponentes fueron Alfredo Gómez, Francisco Ocaranza, Martín Lara, Jorge Moreira, Rómulo Bolaños y Jorge Ortiz. Posteriormente, se dictó la conferencia inaugural 
del destacado historiador y premio Nacional de Historia, Jorge Pinto, quien expuso "La configuración del territorio de Chile en el siglo XIX, su impacto en el pueblo Mapuche y en el conflicto de la Araucanía", tema de tanta relevancia que generó muchas preguntas de los participantes.

A continuación Jorge Ortiz moderó la mesa Choque Cultural, teniendo las exposiciones de Laura Quiroga y Werner Stangl. La última sesión de la tarde y cierre de las exposiciones fueron moderadas por el coordinador, presentando sus ponencias Daniel Correa, Vladimira Palma, Rosa de la Peña y Xochitl Inostroza. La clausura estuvo a cargo del coordinador, quien dio a conocer las conclusiones del evento y las posteriores actividades a realizarse, tanto el tour por la ciudad de Santiago como lo referente a la aplicación webmapping del Atlas digital por medio de la herramienta Story Maps.

El desarrollo de la plataforma del Atlas digital por medio de Story Maps fue una agrupación tanto de diseñador, programador, coordinación y exponentes, quienes dieron vida a esta herramienta interactiva de sus investigaciones. Los textos fueron extraídos directamente de los resúmenes enviados y en concordancia entre una y otra investigación para que no perder la continuidad de la historia narrada, tomando en cuenta que cada una de las investigaciones correspondía a periodos y lugares diferentes.

Con un total de nueve mapas interactivos en la plataforma, más imágenes, gráficos y video, la estructura de Cascada fue facilitando la representación y presentación de cada investigación que integra el Atlas Histórico de América.

A continuación se presentan algunas imágenes de la plataforma, las cuales pueden distinguir en la aplicación webmapping Story Maps a través de la dirección <www.atlashamerica.cl $>$ o directamente en: <https://atlashamerica.maps.arcgis.com/apps/Cascade/index. html?appid=4260950969504d858850d1feb54ece34>.

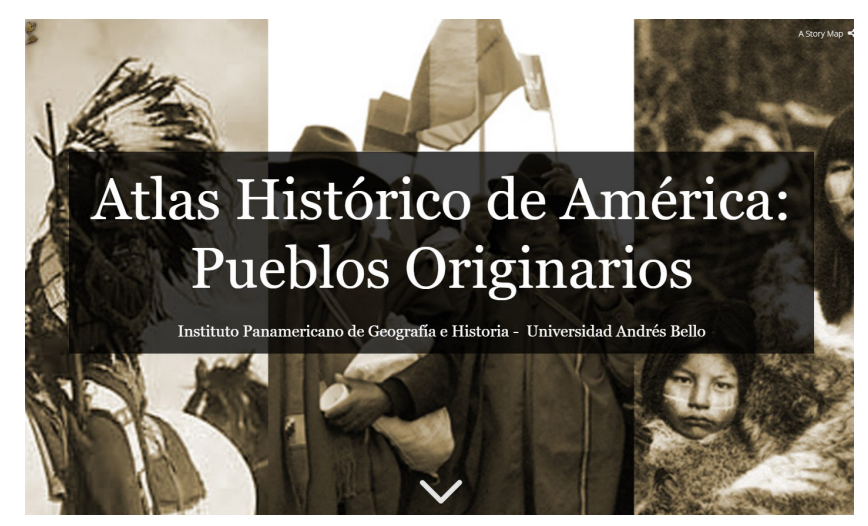

Imagen 7. Portada Atlas interactivo Story Maps. 


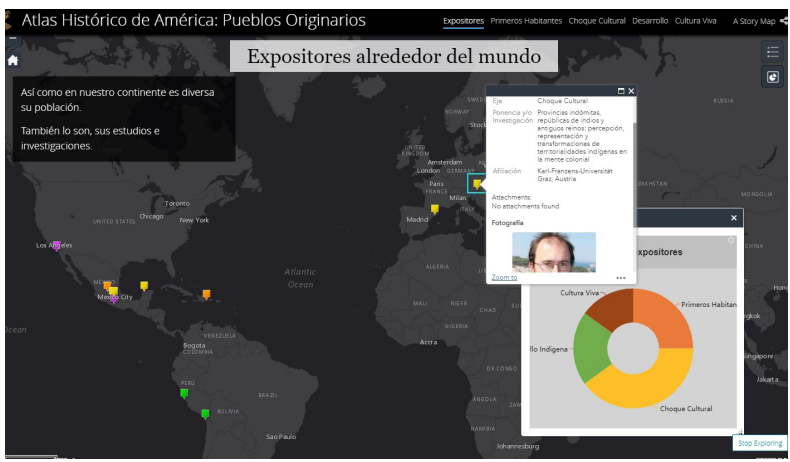

Imagen 8. Mapa interactivo de los expositores al Seminario Internacional.

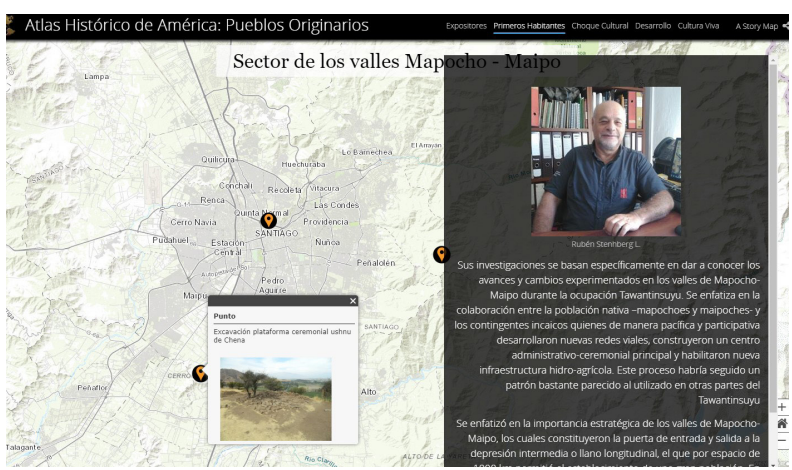

Imagen 9. Mapa interactivo de presentación de ponente Atlas Histórico de América.

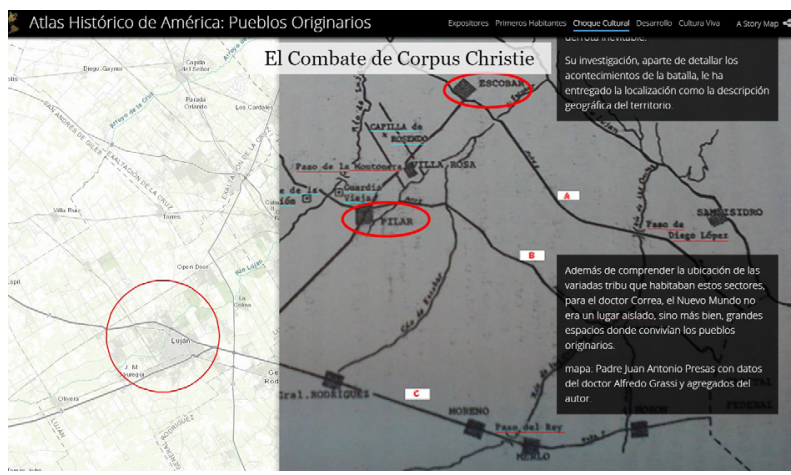

Imagen10. Mapa interactivo con mapa histórico de presentación de ponente Atlas Histórico de América. 


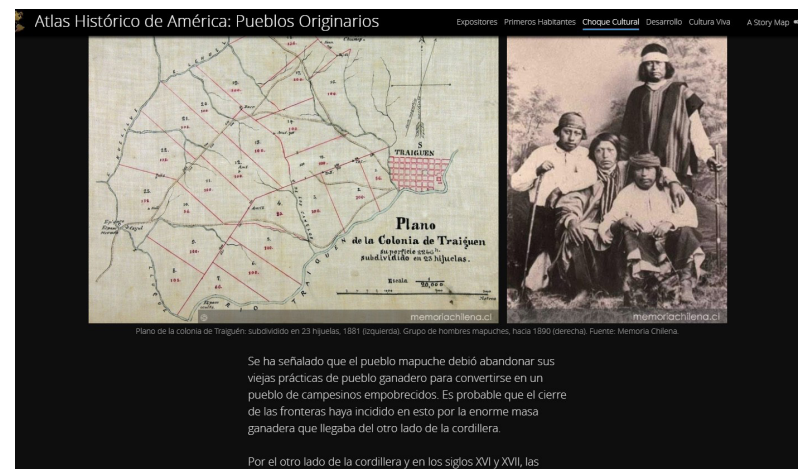

Imagen 11. Imágenes y descripción de presentación de ponente Atlas Histórico de América.

\section{RESULTADOS, CONCLUSIONES Y RECOMENDACIONES}

Como se puede apreciar, el seminario internacional fue un paso para conformar el Atlas interactivo digital. En dicho evento, las experiencias obtenidas en realizar un seminario van de la mano de las actividades y horarios que se ofrecen dictar. Para nuestro caso, nos jugó en contra obtener un mayor público presente, para ambas fechas. Considerando que los estudiantes están cerrando el semestre de actividades y, con ello, comenzando su periodo de exámenes. Pero también, aparte de la gran difusión que se realizó, los eventos de ponencias, clases magistrales y, en este caso, seminarios de las ciencias sociales no hay un interés masivo a participar, problema que debemos remediar como investigadores y académicos de la Historia integrando al público común y no solamente a nuestros pares.

El seminario Atlas Histórico de América: Pueblos Originarios, trató de incluir todas las comunidades y etnias de nuestra región americana. Sin embargo, por la gran diversidad de ellas fue imposible a tan corto plazo (menos de un año) obtener un mayor número de exponentes. Otro de los aspectos que debemos considerar es ampliar la fecha de postulación. La gran mayoría de los seminarios internacionales se realizan cada dos años, pero teniendo aprobados los costes de financiamiento, lo que permite un mayor número de postulaciones.

En lo referente a los contenidos del Seminario y Atlas, si bien se logró presentar investigaciones pertinentes en cada eje temático, las diferencias entre uno y otro denotaban cortes y tiempos entre cada mesa. No obstante, el contenido accedió a obtener el producto deseado integrando tanto la tecnología con las ciencias sociales y abriendo una puerta a otra manera de difundir la educación histórica de nuestra región americana. 
Las conclusiones del seminario pasaron por ampliar la red y, en este caso, obtener la impresión y perspectivas de los verdaderos agentes de estudios, los pueblos originarios. Invitación que debemos acercar para una próxima oportunidad. La representación de un Atlas no puede ser lineal, como nos indicó Federico Navarrete en su conferencia magistral, donde el tiempo y el espacio se conjugan de otra manera para las comunidades indígenas y esta condición debe ser asumida por un nuevo Atlas.

Otro punto a destacar es la relación toponímica que a veces se ha perdido, pero que también se conserva al desarrollar una investigación histórica. Debemos comprender la identidad cultural que ha permitido reservar $y$ conservar las tradiciones indígenas tanto en el espacio - en este caso representado por mapas u otras herramientas que nos permitan ubicarnos por diferentes códigos - como por el tiempo que conlleva a un estudio más acabado de las lenguas, tradiciones, mitos y cosmovisiones de la vida, a veces incluidas en hallazgos arqueológicos, otras en los archivos y, muy a menudo, al acercamiento con nuestras raíces que son los pueblos originarios.

Con respecto al Atlas interactivo, debemos ampliar la educación y el manejo de estas nuevas herramientas; incluirlas en el aprendizaje de las nuevas generaciones proporcionará un contacto directo del devenir de la sociedad actual. Eso sí, tenemos que tomar en cuenta que muchas de estas nuevas tecnologías y, especialmente, la usada en esta plataforma (Story Maps), dependen de licencias y propiedades intelectuales que aumentan los costos de un proyecto y que no pueden ser financiadas por los fondos de una institución (IPGH) ni de una universidad (como es nuestro caso) para el mantenimiento a futuro. Proceso que debemos aprender y establecer en la continuidad de un proyecto, sobre todo cuando queremos ampliar y proseguir con nuevas aportaciones.

Nuestras metas a futuro son realizar el volumen impreso del Atlas Histórico de América: Pueblos Originarios, incluyendo un mayor número de investigadores, lugares y comunidades que no fueron previstas en la primera versión. También nos proponemos apoyar en todo lo necesario para solicitar los fondos y obtener la continuidad del proyecto que llevaría a cargo otro miembro del comité, en este caso el doctor Filiberto Santa Cruz para el proyecto Atlas Histórico de América: Colonia, a realizarse en la ciudad de Santo Domingo en República Dominicana. Esperamos y deseamos la aprobación y el mayor de los éxitos en la continuidad del proyecto. 